\title{
Modeling Collaborative Information Seeking Processes: A Preliminary Study of Team Search Tactics
}

\author{
Zhen Yue \\ School of Information Sciences \\ University of Pittsburgh \\ Pittsburgh, PA, USA \\ zhy18@pitt.edu
}

\author{
Daqing $\mathrm{He}$ \\ School of Information Sciences \\ University of Pittsburgh \\ Pittsburgh, PA, USA \\ dah44@pitt.edu
}

\begin{abstract}
This paper presents an investigation on collaborative information seeking process of team users from the aspect of search tactics. Through the investigation, we identified team search tactics as essential components of collaborative search process. In the study, theory from both information science and social psychology are explored in a preliminary user study to build a conceptual framework of team search tactics, which can be used to guide the design and evaluation of information systems in supporting collaborative information seeking.
\end{abstract}

Keywords- Collaborative information seeking; exploratory search; model; search tactics

\section{INTRODUCTION}

Collaborative information seeking systems need not only support the interaction between user and system, but also support the interaction among users. A successful collaborative information seeking system relies on good understanding of the group activities involved in the information seeking process, and studies which seek to describe collaborative information seeking process can help developers understand the range of behaviors and activities that systems need to accommodate. Search strategies and tactics are important research topics in information seeking study because they are essential components of the search process [1]. Bates [2] proposed the notion of search tactics which consist of a move or moves applied to advance the search process. Although it was intended for use in teaching and facilitating searching, the tactics can be used to analyze what happens in a search process [3]. A search strategy is a plan for the whole search, which can be seen as a series of tactics. As search tactics are essential components of information seeking process, we think that collaborative information seeking process can also be analyzed at the tactical level. However, current search tactic models are all based on individual information seeking. Therefore, the work presented in this paper provides the first step to looking into the team search tactics employed in a collaborative information seeking process. The outcome of our studies is a conceptual framework of team search tactics based on both theory and models of teamwork study and individual search tactics model.

This work was partially supported by the National Science Foundation under Grant No. 0704628 and IIS-1052773.

\section{METHODOLOGY AND STUDY SETTING}

A small scale laboratory study involving two teams was conducted. Each team consisted of two subjects. They were asked to work on an exploratory search task collaboratively. Team members came to the lab for multiple sessions during a two weeks period to complete the task. In the study, we were interested in both face to face and computer-mediated collaborative activities.

\section{A. Experiment Setting}

In this study, we used the data collections and tasks provided by the TREC Legal track, which is a community with motivating goal to apply advanced information retrieval technology in e-discovery. There were two exploratory search tasks performed in this study. The objective of each task was to find all the relevant documents from the corresponding data collection. The data collection for tasks 1 is the Legal Tobacco Document Library (LTDL), which is the standard collection used in the TREC Legal track in 2008 [4]. The data collection for task 2 is the Enron email collection, which is a collection of email messages with attachments. This collection was the standard collection for TREC Legal track in 2009 [5].

Task 1:

All documents which describe, refer to, report on, or mention any "in-store," "on-counter," "point of sale," or other retail marketing campaigns for cigarettes.

Task 2:

All documents or communications that describe, discuss, refer to, report on, or relate to the Company's engagement in structured commodity transactions known as "prepay transactions".

Two pairs of subjects were recruited from the University of Pittsburgh to form two teams working collaboratively on the assigned search task. The two subjects in team 1 are females and the other two subjects in team 2 are males. All of them are experienced searchers and had limited knowledge about the ediscovery task. Task 1 was assigned to team one and task 2 was assigned to team 2. To resemble the complex search process in an e-discovery setting, the study was designed to have multiple sessions. And there was no time limit for the 
subjects to finish the task. Once the team felt that they had reached certain point and wanted to stop, they would call it a session. Normally, each session lasted about two hours. Both pairs of subjects used four sessions until they could finally complete the task.

Throughout each session, subjects in one team were in the same room, back to back, about 10 feet apart. Each of the subjects had a computer and he/she had full control of physical devices such as keyboard and mouse. A search tool very similar to the search engine in the Web and online database environments was used to access the collection and obtaining results. For collaboration purpose, subjects were provided with an instant communication tool that they are already familiar in everyday use. The communication has two functions: 1) sending and receiving instant text messages; 2) screen sharing remotely to show what is on one's screen to the other. The other collaboration tool used in the study was Wiki, which is also commonly used by our subjects in daily life. In the study, wiki was functioned as a shared workspace in which subjects can post and share information. Besides the collaboration tools, subjects were allowed to have face to face communication to facilitate their collaboration.

\section{B. Data Collection and Analysis Method}

Throughout the whole study, we observed the behavior of subjects and took notes about actions or issues we found significant during the process of conducting collaborative search tasks. Also, the chatting history and information posted on wiki page were documented as log data. At the end of each session, each subject filled out a questionnaire with several open-ended questions asking about the details of conducting the task and their feelings and thoughts about the experience and results so far. After the search task was completed for the last session, each team of subjects and the observer formed a focus group to review the study, discuss any particular point in the study and share experience with each other. In this way we could obtain better understanding and explanation of actions that we had observed during the study. Specifically we were interested in the interaction and flow of information between two subjects which contributed to the accomplishment of collaborative task.

The data we collected from the study includes log data of chatting history and wiki pages, observer's notes, subjects' answers to open-ended questions collected in post-session questionnaires and also reports obtained from the focus group. Since all the data were in the form of text, a qualitative content analysis method, which integrates both inductive and deductive reasoning for data analyzing, is used. First, we analyzed the raw data and allow themes to emerge from the data. Then we extended the analysis with meanings and themes in established theory. Two theories were used for content analysis in this study: Bates' search tactics (1979) model and Dickinson \& McIntyre's (1997) teamwork model. The reason of using these two models is to draw inference from them to build the framework of team search tactics.

\section{RESULTS AND DISCUSSION}

Overall subjects thought that e-discovery tasks were complex information seeking tasks for which collaboration was necessary. They claimed that they discovered more than they would have had if they had worked separately in the study. We found that the interaction between subjects in the same team was frequently required and types of collaborative activities varied throughout the whole information seeking process.

The main purpose of this preliminary study was to build a conceptual framework of team search tactics based on both teamwork model and search tactics model. The teamwork model helped to recognize and categorize collaborative activities. Bates' search tactics model was used to examine how search tactics fit into the collaborative activities.

\section{A. Analysis Based on the Teamwork Model}

Dickinson \& McIntyre [6] proposed a teamwork model which is widely used in the social psychology domain. The teamwork model consists of seven components: team leadership, team orientation, monitoring, feedback, back-up, coordination and communication. We observed instances of activities that belong to different teamwork components in our study. Since we only consider two persons teams and they have peer relationship, we didn't observe instance of leadership and back-up. Other than that, we will discuss the instances of collaborative activities according to the components in Dickinson \& McIntyre's teamwork model.

Team orientation. In the study, normally at the beginning, the subjects would discuss the e-discovery task assigned to them. They would identify the context and evaluate the challenges of the task. Team orientation also involved activities centered on the identification of the goals which was to find as many relevant documents as possible. Another typical team orientation activity involved developing courses of actions and plan for the search. For example, one team in the study made a plan at the beginning that each one would try some queries to see what the returning documents are like.

Monitoring. This type of activities including one team member checks the activities and status of the other team member. The purpose might be monitoring the progress of the team toward goals or comparing one's own work to the other team member's work to see whether there were any changes need to make. For instance, a team in the study decided to find useful query terms from the returned relevant documents, in this case, the subject not only spent effort on finding new terms but also paid attention to progress of the team member to make sure they didn't spent time on duplicate documents.

Feedback. Feedback is quite common in the collaborative information seeking. Usually team members would send information they found might be useful to each other. For example, one subject sent a message "check out this document, it has a list of different names for the contracts, should be useful to you". Besides giving feedbacks, team members usually seek for feedbacks too. For instance, one 
subject asked her team member "what does 'No bull' mean, is it the name of a campaign?" We found that feedbacks usually were suggestions of query terms or relevancy of documents.

Coordination. Coordination refers to team members executing the activities in a timely and integrated way. In my study, team members usually coordinated on making plans for dividing and assigning the subtasks. For example, "Do you want to check the results of 'cigarette' and we check 'cigarette' do see which one is better?" Sometimes, the team members also coordinated on the workload of checking the relevancy of the results. One team decided that one subject would view document from screens $1,3,5,7,9$ and the other would look at screens 2, 4, 6, 8, 10.

Communication. Communication is at the core of collaboration. It is the fundamental of the other human-related collaboration. It was common in the study team members communicated to brainstorm ideas. Communication played an important role when team members try to confirm a common ground was reached or a consensus on the decision was made. Besides, communication was also very important for the conflict management between team members.

\section{B. Analysis based on the Search Tactics Model}

Bates (1979) introduced the notion of search tactics, which is a move made to further a search. In her study, 29 search tactics are named, defined, and discussed. The proposed search tactics are intended to be practically useful in information searching. Different types of tactics play different roles in assisting user searching for information and they are classified in four categories: monitoring, file structure, search formulation, and term.

These search tactics are designed to be general and applicable to bibliographic/reference searches in both manual and on-line systems. However, in order to be applicable to collaborative information seeking, this model needs to be reframed for three reasons. First, although some of tactics nonetheless recognize the role of social in information seeking (e.g, to bibble is to take advantage of searches that have been done in the past by other people), most search tactics are only interpreted in individual using context. Therefore, we need to consider how each tactic can be used in collaborative manner. Second, Bates' search tactic model was proposed based on bibliographic and reference searches in library practices. Some tactics like SCAFFOLD and CLEAVE are not commonly used in the Web environment. Third, With regard to the whole set of search tactics, overlapping and some hierarchical relationship will be noticed. Since some search tactics were not used in large numbers, tactics serving similar purpose need to be grouped together. Therefore, we will step through Bates' search tactic to identify commonly used tactics in the Web environment as well as group overlapping tactics. Most importantly, we will identify the scenarios of using these search tactics by team users conducting collaborative search tasks (shown in table 1).
TABLE I

FE-FRAMING BATES' SEARCH TACTICS MODEL

\begin{tabular}{|c|c|c|}
\hline & Individual & Collaborative \\
\hline $\begin{array}{l}\text { MONITORING } \\
\text { TACTICS }\end{array}$ & & \\
\hline CHECK & CHECK & Check team member \\
\hline WEIGH & \multirow{2}{*}{ COMPARE } & \multirow{2}{*}{$\begin{array}{l}\text { Compare with team } \\
\text { member }\end{array}$} \\
\hline PATTEN & & \\
\hline CORRECT & CORRECT & Back-up \\
\hline RECORD & RECORD & Record for share \\
\hline \multicolumn{3}{|l|}{$\begin{array}{l}\text { FILE } \\
\text { STRUCTURE } \\
\text { TACTICS }\end{array}$} \\
\hline BIBBLE & $\begin{array}{l}\text { TRACE SEARCH } \\
\text { HISTORY }\end{array}$ & \multirow{4}{*}{$\begin{array}{l}\text { Refine requirement of } \\
\text { search need Consensus } \\
\text { on decision } \\
\text { Coordination on } \\
\text { parsing result set } \\
\text { Look at other's search } \\
\text { history }\end{array}$} \\
\hline SELECT & SELECT & \\
\hline SURVEY & SURVEY & \\
\hline CUT & CUT & \\
\hline \multicolumn{3}{|l|}{$\begin{array}{l}\text { SEARCH } \\
\text { FORMULATION } \\
\text { TACTICS } \\
\end{array}$} \\
\hline SPECIFY & SPECIFY & \multirow{5}{*}{$\begin{array}{l}\text { Refine requirement of } \\
\text { search need } \\
\text { Plan for search } \\
\text { formulation } \\
\text { Coordination on search } \\
\text { task division }\end{array}$} \\
\hline EXHAUST & EXHAUST & \\
\hline REDUCE & REDUCE & \\
\hline PARALLEL & PARALLEL & \\
\hline PINPOINT & PINPOINT & \\
\hline \multicolumn{3}{|l|}{ TERM TACTICS } \\
\hline SUPER & \multirow{4}{*}{$\begin{array}{l}\text { QUERY } \\
\text { REFORMULATION }\end{array}$} & \multirow{4}{*}{$\begin{array}{l}\text { Seeking and giving } \\
\text { feedback for query } \\
\text { reformulation }\end{array}$} \\
\hline SUB & & \\
\hline RELATE & & \\
\hline NEIGHBOR & & \\
\hline TRACE & TRACE & $\begin{array}{l}\text { Trace other's search } \\
\text { history } \\
\text { Trace saved results }\end{array}$ \\
\hline VARY & \multirow{6}{*}{$\begin{array}{l}\text { QUERY } \\
\text { REFORMULATION }\end{array}$} & \multirow{6}{*}{$\begin{array}{l}\text { Seeking and giving } \\
\text { feedback for query } \\
\text { reformulation }\end{array}$} \\
\hline FIX & & \\
\hline REARRANGE & & \\
\hline CONTRARY & & \\
\hline RESPELL & & \\
\hline RESPACE & & \\
\hline
\end{tabular}

Monitoring tactics. Monitor tactics are very important in collaborative setting because team members need to keep the team progress on track and efficient. CHECK does not only include checking one's own status of search but also team member's progress. WEIGH and PATTERN are both related to making a better decision among choices, thus we group them to COMPARE which is to compare one's own search approaches or patterns with others' in order to make a better choice. CORRECT in a collaborative manner is to offer back up by correcting others' error. RECORD is beneficial in a team work setting with the purpose of recording for sharing.

File structure tactics. Bates submitted that all the information in a typical information facility can be seen as organizing into a structure. "File structure" is used here to refer to the overall pattern or structure of information organization in an information facility. However, how the information is organized on the Web is beyond the knowledge of Web users. They can only make estimations by combining their understanding of requirement/context of search problems with their previous search experiences. Or they can have a 
limited view of the "file structure" by parsing the returned result sets. Therefore, file structure tactics in collaborative environment can be applied when team members have an orientation of current search problems. BIBBLE, SELECT, SURVEY and CUT in the Web environment are also related to looking at other's search history in order to find out what have already been carried out. Team members can also coordinate on sharing the workload of parsing result sets.

Search formulation tactics. The six search formulation tactics relate to formulating search plans, which has been shown as a core activity during collaborative search [7]. To apply these tactics in collaborative setting, team members are required to make plans for the search and coordinated on subtask assignments.

Term tactics. There are overlapping and hierarchical structures in those eleven term tactics. For example, VARY will be seen to be the general case against several specific forms of variation like FIX, REARRANGE, CONTRARY, RESPELL, and RESPACE. Therefore, we group most term tactics to QUERY REFORMULATION. These tactics related to the specific terms used after having formulated a search plan. In most cases, query reformulation is individual decision. However, team members can get feedback on query reformulation or find additional terms by TRACE information other's found.

\section{CONCLUSION}

Based on the previous discussion, we can conclude that search tactics in collaborative search is different from that in the individual search. In an individual search, user needs to focus on his/her own search and try to find the best to complete the search. However, in collaborative search, team members need to be aware of each other's work and try to get benefits from each other so that the teamwork can be more effective. Therefore, a framework of team search tactics is required to reflect the effort towards facilitating collaboration. According to the analysis of collaboration process and collaboration type, the framework should incorporate all types of collaborative activities existing throughout the whole process. Therefore, we propose the following initial framework of team search tactics (Shown in table 2). The categories in our team search tactics framework were proposed based on the previous analysis of Dickinson \& McIntyre's teamwork model. In addition, some tactics were derived from Bates' individual search model but with new meanings, such as CHECK and COMPARE. Some team search tactics can be mapped to a set of tactics in Bates' model. For example, coordination on search formulation is derived from the set of search formulation tactics.

Team search tactics are human efforts made towards advancing collaborative information seeking. Effective collaborative information seeking systems should be designed with capabilities that incorporate these human efforts. Our framework of team search tactics can help system designer to decide what features are highly valued in collaborative information seeking systems.

TABLE II

AN INITIAL FRAMEWORK OF TEAM SEARCH TACTICS

\begin{tabular}{|c|c|}
\hline Orientation & \\
\hline Context framing & $\begin{array}{l}\text { Team members identify and evaluate the context } \\
\text { motivating the search }\end{array}$ \\
\hline $\begin{array}{l}\text { Requirement } \\
\text { refinement }\end{array}$ & Team members iterating on task requirement \\
\hline Planning & Team members make plans for task execution \\
\hline \multicolumn{2}{|l|}{ Communication } \\
\hline Brainstorm & $\begin{array}{l}\text { Team members communicate with each other to } \\
\text { generate new ideas }\end{array}$ \\
\hline Grounding & Team members reach a common ground \\
\hline Conflict Management & Team members deal with conflict \\
\hline Consensus & Team members make agreement on the decision \\
\hline \multicolumn{2}{|l|}{ Coordination } \\
\hline Search formulation & Team members coordinated on divide the search task \\
\hline Parsing result set & Team members coordinated on parsing result set \\
\hline \multicolumn{2}{|l|}{ Monitor } \\
\hline Check & $\begin{array}{l}\text { Team members check each other's progress and } \\
\text { status }\end{array}$ \\
\hline Compare & $\begin{array}{l}\text { Team member compare one's own work with the } \\
\text { other one's }\end{array}$ \\
\hline \multicolumn{2}{|l|}{ Feedback } \\
\hline Giving feedback & One giving feedback to the team member \\
\hline Seeking feedback & One seeking for feedback from the team member \\
\hline
\end{tabular}

The framework of team search tactics proposed in this study is an initial conceptual framework. We will verify and optimize the framework in the future by conducting larger scale of user studies.

\section{REFERENCES}

[1] I. Xie, \& S. Joo, "Transitions in Search Tactics During the Web-Based Search Process," JASIS\&T, vol. 61, pp. 2188-2205, 2010.

[2] Bates, M. J. "Information search tactics", JASIS\&T, vol. 30, pp. 205-214, 1979.

[3] Ingwersen, P., \& Järvelin, K. The turn: integration of information seeking and retrieval in context (p. 448). Springer, 2005, pp. 448.

[4] Oard, D. W., Hedin, B., Tomlinson, S., and Baron, J. R. "Overview of the TREC 2008 legal track", TREC, 2008.

[5] B. Hedin, S. Tomlinson, J. Baron, and D. Oard. "Overview of the TREC 2009 legal track", TREC, 2009.

[6] McIntyre, R. M., with Dickinson T. L. "A conceputal framework of teamwork measurement". In M. T. Brannick, Eduardo Salas, \& C. Prince (Eds.), Team performance assessment and measurement: théory, methods, and applications, Taylor \& Francis, 1997, pp. 331-356.

[7] Wilson, Max L., \& Schraefel, M. C. "Evaluating collaborative information-seeking interfaces with a search-oriented inspection method and re-framed information seeking theory". Information Processing \& Management, vol. 46, pp. 718-732, 2010. 